\title{
V. Note on an error in the method of determining the mean depth of the ocean from the velocity of seismic sea-waves
}

\section{Charles Davison Sc.D. F.G.S.}

To cite this article: Charles Davison Sc.D. F.G.S. (1897) V. Note on an error in the method of determining the mean depth of the ocean from the velocity of seismic sea-waves, Philosophical Magazine Series 5, 43:260, 33-36, DOI: 10.1080/14786449708620955

To link to this article: http://dx.doi.org/10.1080/14786449708620955

曲 Published online: 08 May 2009.

Submit your article to this journal $₫$

Џ Article views: 2

Q View related articles $\sqsubset$ 


\section{$\left[\begin{array}{ll}33 & ]\end{array}\right.$}

V. Note on an Error in the Method of Determining the Mean Depth of the Ocean from the Velocity of Seismio Sea-waves. By Charles Davison, Sc.D., F.G.S., King Edward's High School, Birmingham*.

7 THE data we possess for determining the mean velocity $\mathrm{V}$ 1 of sea-waves are the distance $A$ and the time of transit $T$. From these we obtain

$$
\mathrm{V}=\mathrm{A} / \mathrm{T} \text {. }
$$

We have, from hydrodynamies, the further equation

$$
\mathrm{V}=\sqrt{ }(g \mathrm{H}),
$$

in the case when the sea is of considerable but uniform depth $\mathrm{H}$ along the path traversed by the wave.

If the depth of the sea is variable, it is generally assumed that the quantity $\mathrm{H}$ given by the equation

$$
\sqrt{ }(g \mathrm{H})=\mathrm{A} / \mathrm{T}
$$

is the mean depth of the ocean along the path of the wave. But when the mean depth along the same path can also be obtained from soundings, it is found to be greater than that which is given by the above formula.

In the case of the Krakatoa sea-waves of August 26-30, 1883 , a large number of very careful calculations were made by Capt. W. J. L. Wharton, F.R.S.†; and his results, so far. as they concern the subject of the present paper, are given in the following Table. The stations marked with an asterisk are those at which the records were obtained by automatic gauges. In the second column the figures denote the mean depth of the sea calculated from the formula, and in the last column the mean depth obtained from known soundings.

* Communicated by the Author.

$\uparrow$ "On the Seismic Sea-waves caused by the Eruption of Krakatoa, August 26th and 27th, 1883." "The Eruption of Krakatoa and Subsequent Phenomena,' pp. 89-150.

Phil. Mag. S. 5. Vol. 43. No. 2000. Jan. 1897. 


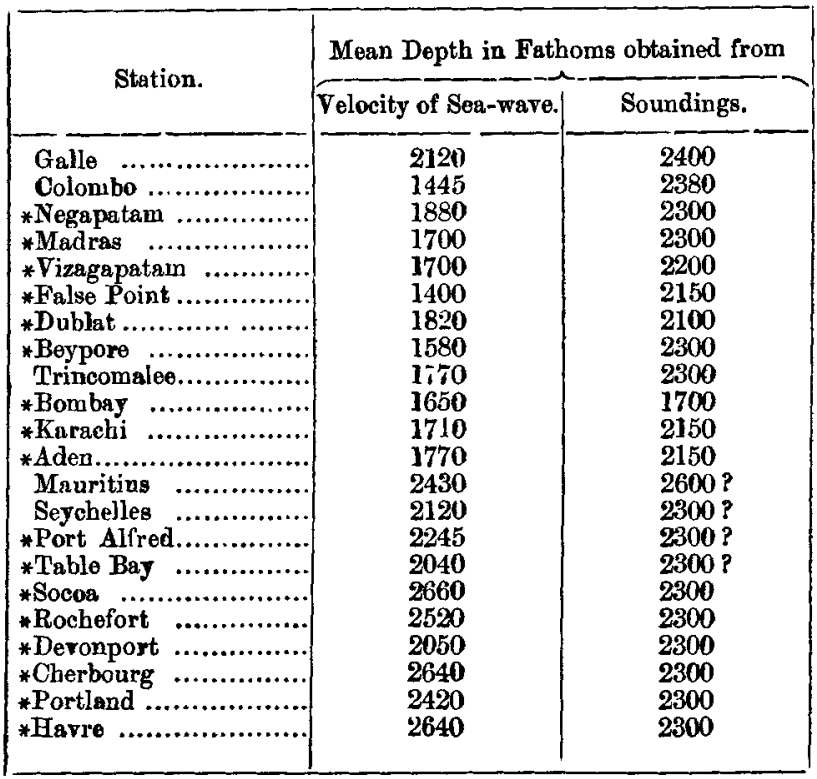

Thus in every case, except along the paths to the six French and English stations, the mean depth obtained from the velocity of the sea-waves is less than that obtained from t'ie soundings. Capt. Wharton does not, however, regard the evidence afforded by any of the six ganges as conclusive. The disturbance in all of them is very slight; though, on the other hand, "looking at them collectively, and seeing the fair accordance of the speed of the waves-which would travel on the same course-the evidence is strongly in favour of the disturbances on these gauges being the effect of one and the same cause, and one which originated at a great distance."

Similar calculations have been made from the waves which accompanied the Iquique earthquake of May 9, 1877+. The disagreement between the mean depths calculated by Dr. Geinitz and Prof. Milne is chiefly due to the different positions of the origin assigned by them to the sea-waves. The values

+ Dr. E. Geinitz, "Das Erdbeben von Iquique am 9 Mai, 1877, und die durch dasselbe verursachte Erdbebenfluth in Grossen Ocean," Nova Acta der Ksl. Leop.-Carol.-Deutschen Akademie der Naturforscher, Bd, xl. 1878 , pp. $385-444$.

Prof. J. Milne, "The Peruvian Earthquake of May 9th, 1877." Japan Seismol. Soc. Trans. vol. ii. 1880, pp. 50-96. Also 'Earthquakes and other Earth Movements,' 1886, pp. 182-186. 
of the mean depth obtained from soundings is calculated from data given by Prof. Milne.

\begin{tabular}{|c|c|c|c|}
\hline \multirow{3}{*}{ Station. } & \multicolumn{3}{|c|}{ Mean Depth in Fathoms obtained from } \\
\hline & \multicolumn{2}{|c|}{ Velocity of Sea-waves. } & \multirow{2}{*}{ Soundings. } \\
\hline & Geinitz. & Milne. & \\
\hline Wellington & 1430 & 1028 & 2473 \\
\hline Honolulu .................... & 2319 & 1635 & 2495 \\
\hline Samoa & 1930 & 1662 & 2500 \\
\hline Kamaishi .................... & 2182 & 1563 & 2584 \\
\hline
\end{tabular}

Both Captain Wharton and Prof. Milne notice the discrepancy between the calculated and observed mean depths, and both offer a partial explanation of it. According to the latter, "the common error in actual soundings is that they are usually too great, it being difficult in deep-sea sounding to determine when the lead actually reaches the bottom." Daptain Wharton remarks that " any unknown ridges would diminish the speed; but these must be large, or the portion of the wave overlapping them would still travel at the speed due to deeper water, and over a very slightly longer course."

But even if the soundings were absolutely exact, and if there were no unknown ridges, the discrepancy would still exist ; for, as will be shown below, the assumption that the mean depth of the sea is given by the equation $\sqrt{ }(g \mathrm{H})=\mathrm{A} / \mathrm{T}$ is incorrect.

Taking the tide-gauge as the origin, the horizontal line joining the gauge and the epicentre as the axis of $x$, and the axis of $y$ vertically downwards, then, neglecting the curvature of the earth,

and therefore

$$
\mathrm{T}=\frac{1}{\sqrt{ } g} \int_{0}^{\mathrm{A}} \frac{d x}{\sqrt{ } \boldsymbol{y}},
$$

$$
\mathrm{H}=\left(\frac{\mathrm{A}}{\int_{0}^{\mathrm{A}} \frac{d x}{\sqrt{ } y}}\right)^{2} \text {. }
$$

Also, D being the true mean depth,

$$
\mathrm{D}=\frac{1}{\mathrm{~A}} \int_{0}^{\mathrm{A}} y d x,
$$


and

Let

$$
\overline{\mathrm{D}}=\int_{0}^{\mathrm{A}} y d x \times\left(\int_{0}^{\mathrm{A}} \frac{d x}{\sqrt{ } y}\right)^{2} \div \mathrm{A}^{3} .
$$

where

$$
\int_{0}^{A} y d x=h_{1} a_{1}+h_{2} a_{2}+\ldots+h_{n} a_{n}
$$

Then

$$
a_{1}+a_{2}+\ldots+a_{n}=\mathrm{A} .
$$

$$
\begin{aligned}
\int_{0}^{\Lambda} y d x & \times\left(\int_{0}^{\Lambda} \frac{d x}{\sqrt{ } y}\right)^{2}-\mathrm{A}^{3} \\
= & \left(h_{1} a_{1}+h_{2} a_{2}+\ldots+h_{n} a_{n}\right) \times\left(\frac{a_{1}}{\sqrt{h_{1}}}+\frac{a_{2}}{\sqrt{h_{2}}}+\ldots+\frac{a_{n}}{\sqrt{h_{n}}}\right)^{2} \\
=\Sigma\left\{a _ { 1 } a _ { 2 } ^ { 2 } \left(\frac{h_{1}}{h_{2}}+2 \sqrt{\left.\left.\frac{h_{2}}{h_{1}}-3\right)\right\}}\right.\right. & -\left(a_{1}+a_{2}+\ldots+a_{n}\right)^{3} \\
& \quad+\Sigma\left\{2 a_{1} a_{2} a_{3}\left(\frac{h_{1}}{\sqrt{h_{2} h_{3}}}+\frac{h_{2}}{\sqrt{\overline{h_{3} h_{1}}}}+\frac{h_{3}}{\sqrt{h_{1} h_{2}}}-3\right)\right\} .
\end{aligned}
$$

It may be easily shown that the coefficients of $a_{1} a_{2}^{2}$ and $a_{1} a_{2} a_{3}$ are positive. Hence $\mathrm{D}$ is greater than $\mathrm{H}$, unless $y$ is constant.

To obtain a numerical estimate of the inequality between $\mathrm{D}$ and $\mathrm{H}$, I have taken the case of a cylindrical ocean-bed, whose right section is a parabola, the breadth of the ocean 1200 miles, its greatest depth 4 miles, and (for simplicity) I supposed the tide-gauge and the epicentre of the earthquake to be equidistant from the axis of the parabola, the depth of water at each place being one quarter of a mile. The true mean depth of the ocean along the path of the sea-wave is then 2420 fathoms, and the mean depth as calculated from the velocity of the sea-wave is 1900 fatboms, the latter number being about three quarters of the former.

VI. On the Estimation of "Waste Space round the Needle of a Galvanometer." By ANDREw GRAY, LL.D., F.R.S., Professor of Physics in the University College of North Wales*.

MY attention has been recalled to Professor Holman's I paper in the Philosophical Magazine for December 1895 by the reply from Professor Ayrton and Mr. Mather which appeared in the November number of 1896. In that

* Communicated by the Author. 